\title{
Ongoing outbreak of rubella among young male adults in Poland: increased risk of congenital rubella infections
}

I Paradowska-Stankiewicz ${ }^{1}$, M P Czarkowski ${ }^{1}$, T Derrough², P Stefanoff (pawel.stefanoff@fhi.no)3,4

1. National Institute of Public Health - National Institute of Hygiene, Warsaw, Poland

2. European Centre of Disease Prevention and Control (ECDC), Stockholm, Sweden

3. Norwegian Institute of Public Health, Oslo, Norway

4. European Programme for Intervention Epidemiology Training (EPIET), European Centre for Disease Prevention and Control $(E C D C)$, Stockholm, Sweden

Citation style for this article:

Paradowska-Stankiewicz I, Czarkowski MP, Derrough T, Stefanoff P. Ongoing outbreak of rubella among young male adults in Poland: increased risk of congenital rubella infections. Euro Surveill. 2013;18(21):pii=20485. Available online: http://www.eurosurveillance.org/ViewArticle.aspx?Articleld=20485

From January to April 2013, Poland reported 21,283 rubella cases (55.2 per 100,000 inhabitants), the highest number since 2007 . Some $81 \%$ of cases were among 15-29 year-old males. This outbreak reflects the history of immunisation policies - selective vaccination of adolescent girls since 1989, then universal two-dose measles-mumps-rubella vaccination, since 2004. The extent of virus circulation among adults increases the risk of congenital rubella infections and jeopardises the World Health Organization Regional Office for Europe 2015 elimination goal.

\section{Ongoing rubella outbreak}

From January to April 2013, physicians in Poland notified 21,283 rubella cases $(55.2$ per 100,000 inhabitants) [1], a near 10 -fold increase compared with the 2,224 cases (5.8 per 100,000 inhabitants) reported during the corresponding period of 2012 (Figure 1).

Physicians use the European Union (EU) case definitions for rubella and congenital rubella syndrome (CRS) [2]. They report each rubella case to the local health department, providing demographic information, International Classification of Diseases (ICD)-10 code [3], case classification and vaccination status. Every two weeks, local health departments report the number of cases notified in their area to the provincial health departments that aggregate data, which they forward to the National Institute of Public Health - National Institute of Hygiene. Every month, local health departments prepare aggregated reports with more detailed data including the number of cases by age group, sex, vaccination status and case classification.

Physicians report CRS cases to the local health departments. Local health departments investigate CRS cases and send individual reports to the National Institute of Public Health - National Institute of Hygiene. There is no routine active case finding search for CRS cases, nor has active CRS surveillance been implemented to date.
We describe here this country-wide rubella outbreak by person, place and time and propose implementation of preventive measures.

We calculated reported rates per 100,000 inhabitants, dividing the number of rubella reported cases by midyear census estimates [4]. The reported rates of rubella varied substantially between provinces (median: 51.2 per 100,000 inhabitants; range: 7.4-151.1 per 100,000 inhabitants). The majority of cases were reported from three provinces in the south-east of the country $(n=8,659 ; 41 \%)$, bordering Ukraine, Belarus and Slovakia, and five provinces in the north-west $(n=7,997$; $38 \%$ ), two of which border Germany (Figure 2).

The male to female ratio was 10:1. The most affected groups were persons who were male aged 15-19 years $(12,220$ cases, reported rate: $1,044.9$ per 100,000 inhabitants; $57 \%$ of cases), $20-24$ years (4,000 cases, reported rate: 286.8 per 100,000 inhabitants; $19 \%$ of cases) and 25-29 years (992 cases, reported rate: 61.1 per 100,000 inhabitants; $5 \%$ of cases). During 2003 to 2012 and the first four months of 2013, rubella reported rates suggested an increasing trend in 2006-2007 and then in 2012 and the first third of 2013. The increases in 2006-2007 and from 2012 were both more pronounced among males 10 years of age and older, especially in the first four months of 2013 (Figure 3).

Vaccination status was recorded for 15,237 (72\%) reported cases. Of these, $1,502(10 \%)$ were vaccinated with one dose of rubella-containing vaccine, and 234 ( $2 \%)$ with two or more doses of rubella-containing vaccine.

Of all reported cases, 29 (0.1\%) were confirmed (based on a valid laboratory test), 57 (0.3\%) were probable (based on an epidemiological link to a confirmed case), and 21,197 (99.6\%) were possible (based on clinical symptoms). 


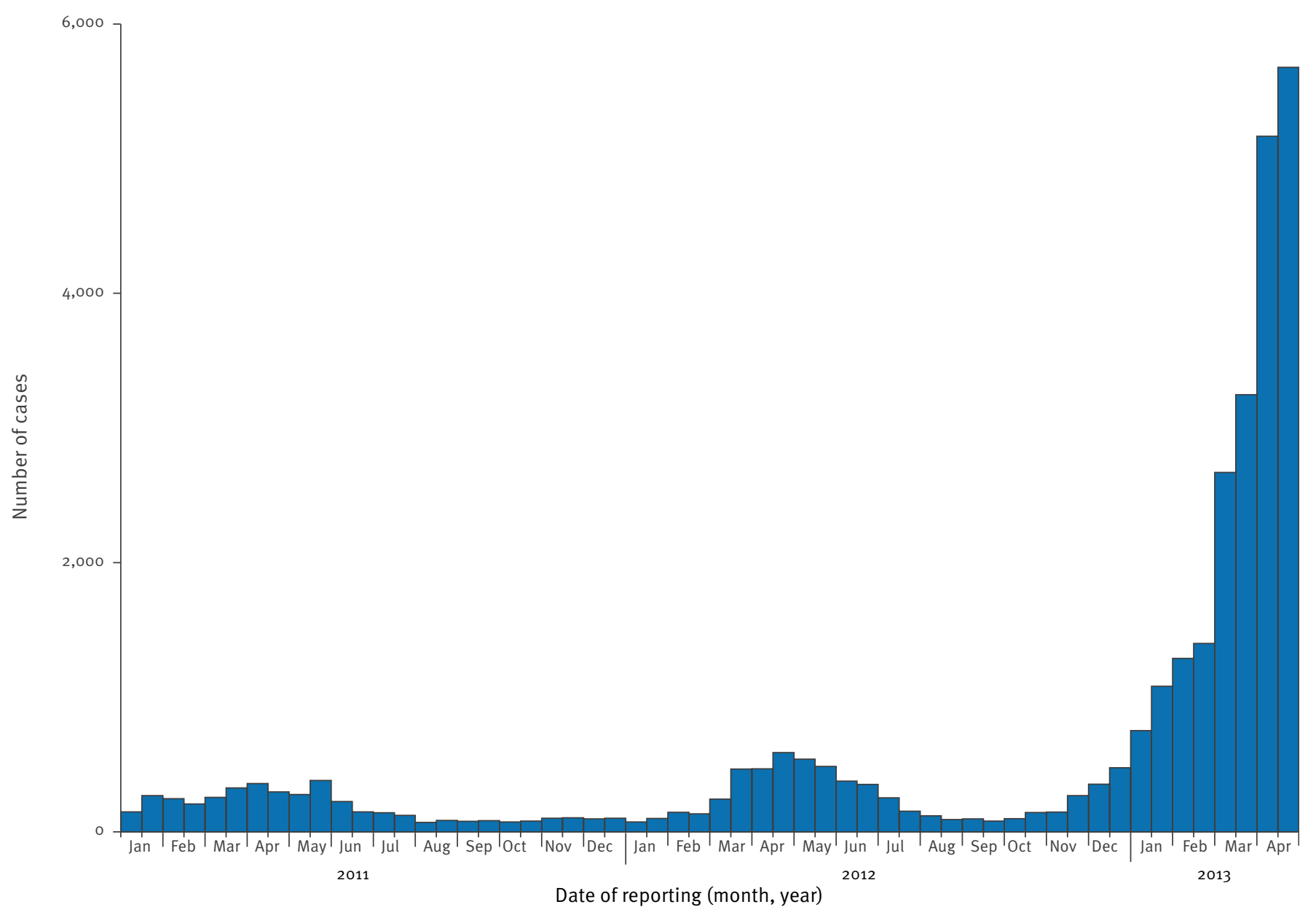

From January to April 2013, two cases of (CRS) were reported, as compared with four cases reported during 2003 to 2012.

\section{History of rubella immunisation in Poland} In 1989, Poland started to administer monovalent rubella vaccine to 13 year-old girls. In 1992-2006, reported coverage ranged from $94 \%$ to $99 \%$ [5]. In 2004, measles-mumps-rubella (MMR) vaccine was administered to all children at the age of 13-15 months and 10 years [1]. In 2005-2012, first-dose coverage among 3 year-old children ranged from $91 \%$ to $98 \%$ [5].

In 2011, a mission of the World Health Organization (WHO) Regional Office for Europe reviewed the rubella situation in Poland, identified an immunity gap among adolescent males and young adults and recommended supplementary immunisation of all adolescents and young adults, as the increased circulation of rubella among young adults increases the risk of congenital rubella syndrome (CRS) [6].

\section{Discussion}

The 2013 outbreak of rubella in Poland reinforces the need for public health efforts to meet the WHO Regional Office for Europe target for the elimination of measles and rubella and prevention of CRS by 2015 [7]. From April 2012 to March 2013, rubella cases in Poland comprised $74 \%$ of those in the EU/European Economic Area (EEA) countries [8]. Despite the visible impact of the childhood immunisation programme in decreasing rubella activity among the vaccinated age groups, Poland will not achieve rubella elimination without targeted supplementary immunisation activities.

The outbreak reflects the historical immunisation activities in Poland: a combination of selective and universal vaccination led to a shift in the age of rubella infections to cohorts of young adults. This situation increases the risk for CRS, due to high circulation of the rubella virus among adolescents and young adult populations. Despite long-term vaccination of adolescent girls, about $10 \%$ of women of childbearing age may still be susceptible to rubella, as documented in a 2004 study [9]. From January to April 2013, two 
Reported rates of rubella by province, Poland, 1 January-30 April 2013 ( $n=21,283)$
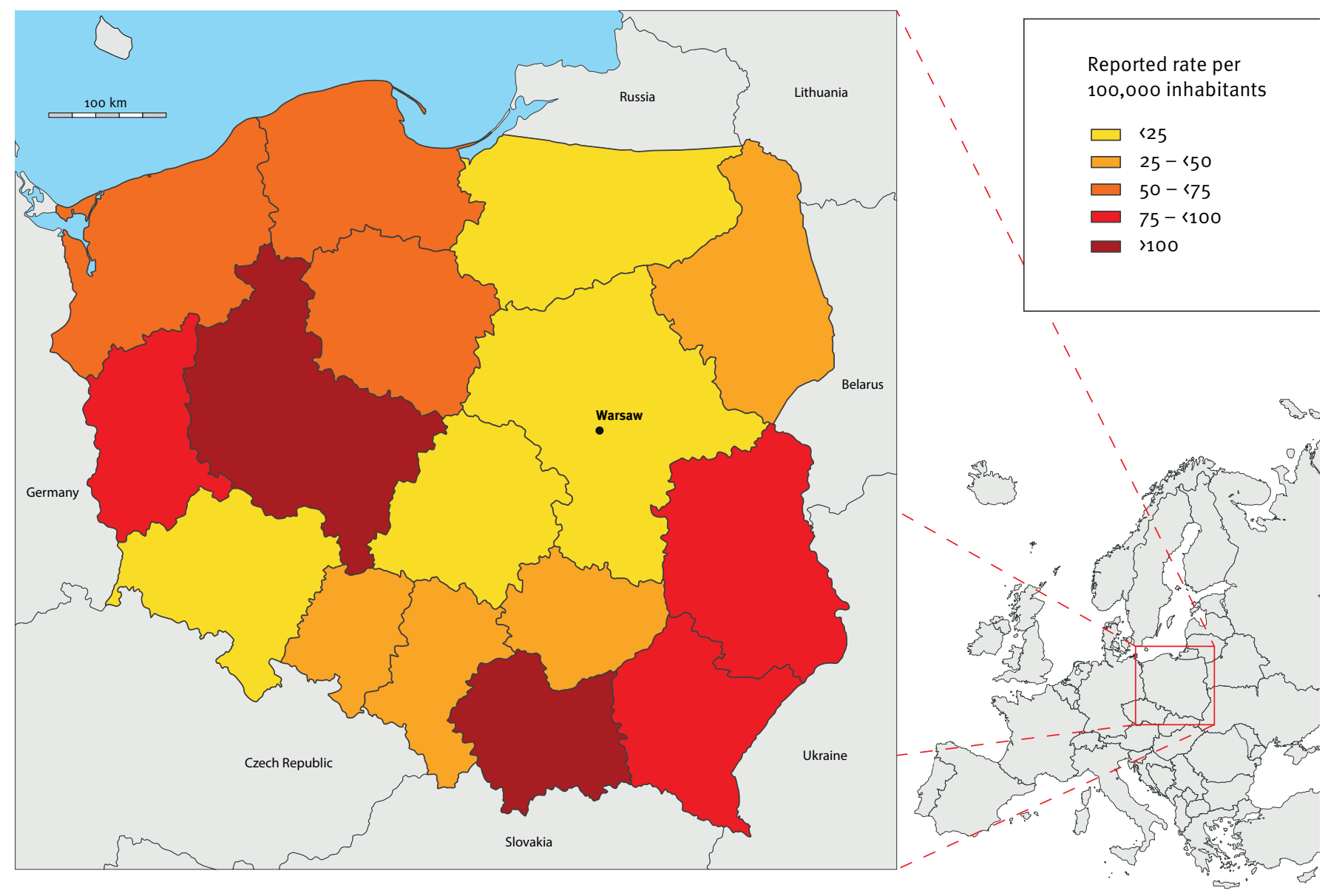

cases of CRS have already been reported, as compared with four cases during 2003 to 2012. Further cases are unfortunately expected and unavoidable, as observed during outbreaks in other EU/EEA countries in recent years. The country most recently affected was Romania. In 2011-2012, Romania reported 20,772 rubella cases, 22 confirmed CRS cases and 11 cases of congenital rubella infection $[10,11]$. A similar situation was observed in Greece in the 1990s: a large rubella outbreak was described in 1993, with 25 cases of CRS, and another epidemic occurred in 1999, mainly in young adults, with four cases of CRS [12]. These observations in Greece, Romania and now Poland are a consequence of immunisation practices that had been followed, leading to the build-up of susceptible cohorts. Sadly, rubella outbreaks in young adults unavoidably lead to children being born with CRS. This situation is likely to be repeated if women of childbearing age are left unprotected and become infected with the rubella virus. All possible efforts should be undertaken to prevent any cases of CRS in Europe in the future. The availability of rubella-containing vaccines with a long-standing history of good safety and effectiveness profiles, and provision to all those who need it would ensure that the potentially dramatic consequences of rubella infection in pregnancy would become a thing of the past.

Effective control of rubella and prevention of CRS requires high-level political commitment and a longterm strategy for vaccination programmes and implementation of additional control measures, when needed. The WHO Region of the Americas elaborated a regional plan of action and mobilised human and financial resources in support of a rubella and CRS elimination goal for 2010 [13]. In 2009, the last endemic rubella and CRS cases in that region were reported. Since then, rubella cases have been attributed to importations of rubella virus into countries, particularly those that only targeted girls for vaccination. In response to these outbreaks, countries reinforced surveillance activities and vaccination interventions by conducting supplementary immunisation activities among adolescents and adults. The results of a systematic literature review demonstrated that the combined vaccination strategy with a universal approach - two doses of rubella-containing 
Trends in age group-specific reported rates of rubella, Poland, 1 January 2003-30 April 2013

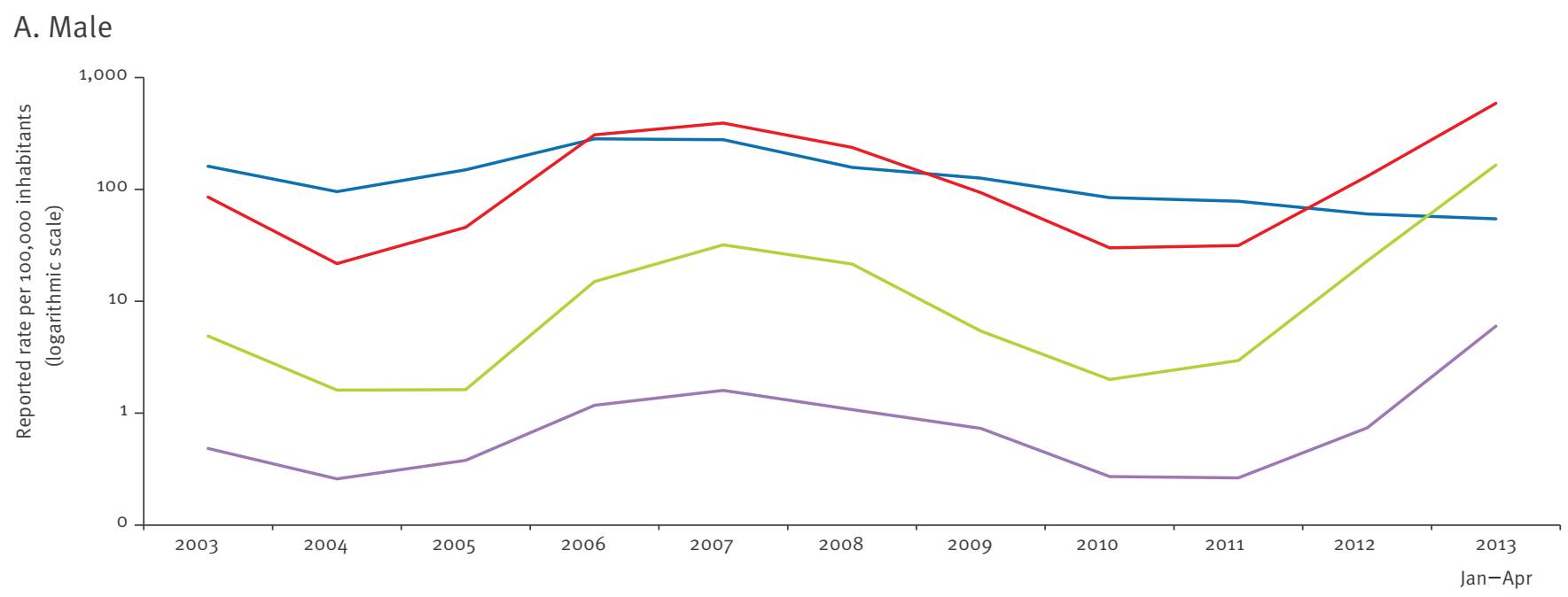

B. Female

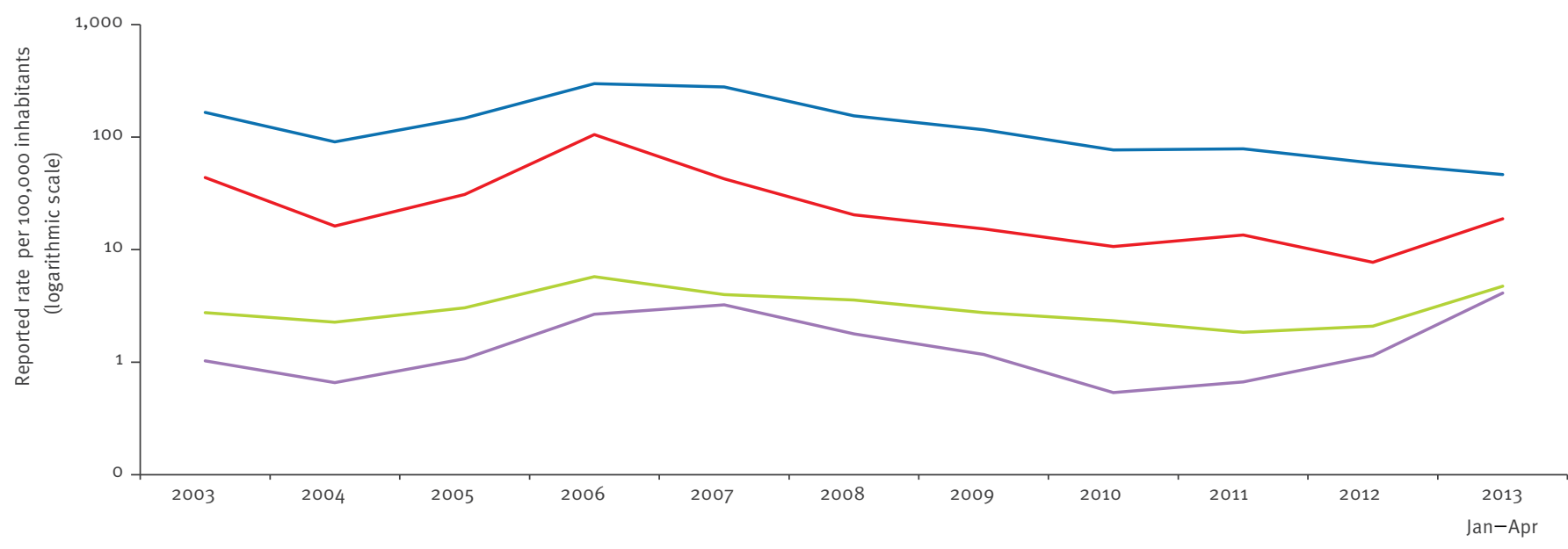

Age group (years): $\quad-0-9 \quad 10-19 \quad 20-29 \quad \geq 30$

vaccine in children 1-6 years of age and one dose in susceptible adult (both men and women) populations through a catch-up campaign - contributed to the elimination of rubella in the Americas, as observed in Costa Rica and in Mexico [14].

Our report has one main limitation. The vast majority of cases were reported based on clinical symptoms and were not laboratory confirmed. Thus, the clinical cases could be potentially due to a concomitant outbreak of another illness causing a rash. Elements that support the hypothesis of a rubella outbreak include: (i) the unvaccinated status of most reported cases and (ii) their age-by-sex distribution. Therefore, rubella remains the most probable explanation for this outbreak.
This outbreak empirically reflects the shift in the age of infections and the accumulation of susceptible cohorts, 10 years after starting universal vaccination. The increased age of infected people leads to an increased risk of CRS. This situation requires immediate public health action to prevent further CRS cases.

\section{Suggested public health action}

First, we suggest that rubella elimination and CRS prevention should be made a priority and a plan of action developed. Second, the proportion of laboratory-investigated cases should be increased, to confirm the aetiology of the outbreak. Third, we suggest enhancing the surveillance of congenital rubella infections to monitor the impact of interventions and to estimate the CRS burden. Fourth, following confirmation of the rubella aetiology of this outbreak, emergency catch-up vaccination of young adults should be considered, to stop 
further transmission of the virus and prevent further CRS cases. Fifth, we suggest screening for rubella antibodies as part of pre-conception or antenatal care to identify and vaccinate unprotected women [15]. Sixth, a seroprevalence study could be instrumental in documenting the age-specific proportion of susceptible persons after the outbreak.

\section{Acknowledgements}

We would like to thank Yvan Hutin for his very helpful comments and suggestions for the manuscript.

\section{Conflict of interest}

None declared.

\section{Authors' contributions}

Iwona Paradowska-Stankiewicz and Miroslaw Czarkowski were responsible for data collection, verification and summarisation. Pawel Stefanoff and Tarik Derrough drafted the manuscript. All authors revised and approved the final version of the manuscript.

\section{References}

1. National Institute of Public Health - National Institute of Hygiene (NIPH - NIH), Chief Sanitary Inspectorate. Dwutygodniowe meldunki o zachorowaniach na choroby zakaźne, zakażeniach i zatruciach w Polsce. [Bi-weekly reports on infectious diseases and poisonings in Poland, 2013]. Warsaw: NIPH - NIH. [Accessed 12 May 2013]. Polish. Available from: http://www.pzh.gov.pl/oldpage/epimeld/2013/ index mp.html

2. European Commission. Commission decision of 19 March 2002 laying down case definitions for reporting communicable diseases to the Community network under Decision No 2119/98/EC of the European Parliament and of the Council. Official Journal of the European Union. Luxembourg: Publications Office of the European Union. Communities. 3.4.2002:L 86/44. Available from: http://eur-lex.europa.eu/ LexUriServ/LexUriServ.do?uri=0J:L:2002:086:0044:0062:EN: PDF

3. World Health Organization (WHO). Mental and behavioural disorders. Clinical descriptions and diagnostic guidelines. In: International statistical classification of diseases and related health problems 10th revision. Geneva: WHO; 2010. Available from: http://apps.who.int/classifications/icd10/browse/2010/ en

4. Poland Central Statistical Office. Bank Danych Lokalnych. [Local databank]. Warsaw: Poland Central Statistical Office. [Accessed 22 May 2013]. Polish. Available from: http://www. stat.gov.pl/bdl/app/strona.html?p_name=indeks

5. National Institute of Public Health - National Institute of Hygiene (NIPH - NIH), Chief Sanitary Inspectorate. Vaccinations in Poland, 1999-2012. Warsaw: NIPH - NIH. [Accessed 22 May 2013]. In Polish, partly in English. Available from: http://www. pzh.gov.pl/oldpage/epimeld/index_a.html\#05

6. Zimmerman L, Rogalska J, Wannemuehler KA, Haponiuk M, Kosek A, Pauch E, et al. Toward rubella elimination in Poland: need for supplemental immunization activities, enhanced surveillance, and further integration with measles elimination efforts. J Infect Dis. 2011;204 Suppl 1:S389-95.

7. World Health Organization (WHO) Regional Office for Europe. Renewed commitment to measles and rubella elimination and prevention of congenital rubella syndrome in the WHO European Region by 2015. Copenhagen: WHO Regional Office for Europe; 23 July 2010. Available from http://www.euro.who. int/__data/assets/pdf_file/0008/119546/RC60_edoc15.pdf

8. European Centre for Disease Prevention and Control (ECDC). Measles and rubella monitoring. May 2013. Stockholm: ECDC; 2013. Available from: http://ecdc.europa.eu/en/publications/ Publications/measles-rubella-monitoring-may-2013.pdf
9. Wysokiñska T, Janaszek W, Bucholc B, Gorska P, Gniadek G, Slusarczyk J, et al. The prevalence of anti-rubella antibodies in women of childbearing age in Poland. Vaccine. 2004;22(15-16):1899-902.

10. Janta D, Stanescu A, Lupulescu E, Molnar G, Pistol A. Ongoing rubella outbreak among adolescents in Salaj, Romania, September 2011-January 2012. Euro Surveill. 2012;17(7):pii=20089. Available from: http://www. eurosurveillance.org/ViewArticle.aspx?Articleld=20089

11. Romanian National Institute of Public Health. Supravegherea IRC/SRC, Romania, 2012. [Surveillance of congenital rubella infection and syndrome, Romania, 2012]. [Accessed 22 May 2013]. Romanian. Available from http://www.insp.gov. ro/cnscbt/index.php?option=com_docman\&task=doc_ download\&gid $=504$ \& Itemid $=14$

12. Panagiotopoulos T, Antoniadou I, Valassi-Adam E. Increase in congenital rubella occurrence after immunisation in Greece: retrospective survey and systematic review. BMJ. 1999;319(7223):1462-7. http://dx.doi.org/10.1136/bmj.319.7223.1462

13. Pan American Health Organization (PAHO). Plan of action for maintaining measles, rubella, and congenital rubella syndrome elimination in the Region of the Americas. Washington, DC: PAHO; 2012. Available from: http://new.paho.org/hq/index. php?option=com_docman\&task=doc_download\&gid $=18542 \& \mathrm{i}$ temid $=\&$ lang $=$ en

14. Mongua-Rodriguez N, Díaz-Ortega JL, García-García L, Piña-Pozas M, Ferreira-Guerrero E, Delgado-Sánchez G, et al. A systematic review of rubella vaccination strategies implemented in the Americas: impact on the incidence and seroprevalence rates of rubella and congenital rubella syndrome. Vaccine. 2013;31(17):2145-51. http://dx.doi.org/10.1016/j.vaccine.2013.02.047 PMid:23470237

15. Di Mario S, Basevi V, Gori G, Spettoli D, et al. What is the effectiveness of antenatal care? (Supplement). Copenhagen: World Health Organization (WHO) Regional Office for Europe (Health Evidence Network report); 2005. Available from: http:// www.euro.who.int/_data/assets/pdf_file/0005/74660/ E87997.pdf 